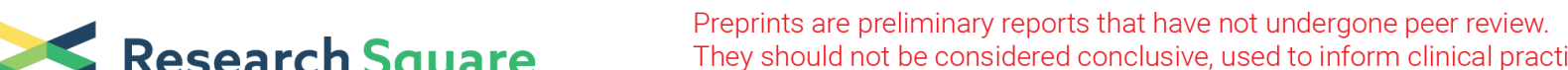 Research Square They should not be considered conclusive, used to inform clinical practice, or referenced by the media as validated information.
}

\section{Distribution, Source finding, ecological hazard assessment and water-sediment exchange rate of polychlorinated biphenyl compounds (PCBs) in South Pars Industrial Zone, Iran}

\section{Alireza Ghadrshenas}

Department of Environment, Branch Bushehr, Islamic

\section{Tayebeh Tabatabaie}

Department of Environment, Branch Bushehr, Islamic

Fazel Amiri ( $\sim$ famiri@iaubushehr.ac.ir)

Department of Environment, Branch Bushehr, Islamic Azad University, Bushehr, Ir https://orcid.org/0000-0003-0941-9679

Abdul Rahim Pazira

Department of Environment, Branch Bushehr, Islamic

\section{Research Article}

Keywords: Polychlorinated biphenyls (PCBs), Particulate matter, Ecological hazard assessment (EHA), Coastal zone, Seawater-sediment exchange

Posted Date: March 1st, 2022

DOI: https://doi.org/10.21203/rs.3.rs-1390048/v1

License: (c) (i) This work is licensed under a Creative Commons Attribution 4.0 International License. Read Full License 


\section{Abstract}

South Pars Industrial Zone is located near an Assaluyeh city on the coast of the Persian Gulf and is known as the energy capital of Iran. In this study, environmental and health effects due to PCB components had an assessment. In this study, 10 air stations, 10 seawater, and sediments stations were systematically selected and sampled in two seasons. Air, seawater and sediment pollution made by polychlorinated biphenyls (PCBs) were evaluated. Seawater-sediment exchange conditions using the fugacity coefficient reviewed. PCB levels in marine sediments, seawater, and air-based on the analysis of the obtained data were 107.33-172.92 ng / g, ND-135.68 $\mathrm{\mu g} / \mathrm{l}$, and ND-4.4 ng / m3, respectively. The highest concentration was observed in the vicinity of refineries, petrochemicals, and petroleum export facilities. These values had increased significantly compared to values of studies, conducted in similar areas. The sources were electrical wastes, storage sites, power generation units, and wastewater treatment. The ecological risk of seawater was assessed to be high, while sediment risks were reported with a low to moderate risk range. The heavier compounds with more chlorine were moved from sediments to seawater and, showed that seabed acted as a secondary source of sea pollution. Lighter compounds with less chlorine moved toward the sediments, from the seawater, and the seabed acted as a sink for these compounds. It is suggested for the area to be continuously monitored while engineering and management measures should be adopted to improve the situation and also prevent the spread of pollution.

\section{Highlights}

- Spatial distribution of PCBs in South Pars region.

- First PCBs ecologic risk assessment in South Pars Industrial Zone coastal sediment.

-The seabed acts like a sink for low-chlorine PCB compounds

- Sediments act as a secondary source for high-chlorine PCB compounds

- Significant increase in pollutants, especially carcinogenic compounds, was shown in the vicinity of industrial units.

\section{Introduction}

Polychlorinated biphenyls compounds (PCBs) because of their special properties have long been produced under various brands (e.g. Arocore oil) in industrialized countries and were widely used in industries such as heat exchangers, pesticides, cosmetics, hydraulic lubricating oils, dyeing, plastics, paints, adhesives, carbonless copy paper, capacitors, transformer oils, circuit breakers and fluorescent lamps(Erickson et al. 2011). 
Although initially thought by manufacturers to be harmless, the widespread adverse effects on human health and the environment have been reported including embryonic abnormalities, fetal stillbirth, accumulation in the leaves and roots of plants, microorganisms' body, fish, suffocation, and malnutrition, false satiety of turtles, birds, and animals.

These compounds were identified as the main cause of cancer due to their properties such as hydrophobicity, carcinogenicity, the tendency to fat, and stability in the environment as organic environmental pollutants with very high toxicity potential (Aghadadashi et al. 2019Löf et al. 2016). All compounds of PCBs have been announced to be carcinogenic by the US International Environmental Protection Agency (Farrington. 2020). Following the disclosure of high levels of pollution and their effects on human and environmental health, their production were proscribed since 1972 and excluded from global consumption by the international community in 1977(Maung et al. 2021).

However, there is still their potential or possible entry into the environment since they are available in huge amounts in warehouses and various devices. Currently, 83\% of produced PCBs are still remaining and need to be removed according to the estimates of the United Nations Environment Program (UNEP)(EPA. Mahmoudi et al. 2020). Contamination with PCB compounds is not limited to a specific geographical location; air, water, soil and sediment pollution is observed by these compounds worldwide.

Contamination with PCB compounds is not limited to a specific geographical location, air, water, soil and sediment pollution is observed by these compounds worldwide. (Sakizadeh. 2020) The following are some examples.

In 2009, a study on an area of $19 \mathrm{~km}$ in London reported the concentration of PCBs in urban soil to be 9$2600 \mu \mathrm{g} / \mathrm{kg}$, which was higher than that in other similar cities In a study conducted on a coastal industrial area in Turkey in 2017, PCB concentration values of air, seawater, and coastal sediments were found 104$20083 \mathrm{pg} / \mathrm{m}^{3}, 880 \mathrm{pg} / \mathrm{l}$, and $2.7-2450 \mathrm{ng} / \mathrm{g}$ dry weight (ng/g.dw), respectively. The predominant transfer of these pollutants was observed from seawater to air(60.6\%) in the vicinity of industrial units(Odabasi et al. 2017)

Nozar et al. measured the PCB level in the coastal sediments of the northern Persian Gulf and announced that $10.3 \%$ and $2.9 \%$ of the obtained concentrations were higher than the effects of Range-Low (ERL) and the effects of Range-Median (ERM), respectively(Nozar et al. 2014) The level of PCB contamination in the fish of Lark Coral Island in the Persian Gulf was reported by Ranjbar et al. to be in the range of 2.95-7.95 ng / g body weight.(Ranjbar Jafarabadi et al. 2019) In 2009, the concentrations of PCBs in coastal water and sediments in the southwest of the Persian Gulf were reported 8-7375 ng/l and $50-3.4 \mu \mathrm{g} / \mathrm{g}$, respectively (Zahed et al. 2009). (Zahed et al. 2009).

In studies on coastal sediments of Bahrain, the highest concentration $(0.88 \mathrm{ng} / \mathrm{g} . \mathrm{dw})$ was observed in the vicinity of refineries (Bersuder et al. 2020). In a study on the contamination of plastic resin pellets (plastic waste) on the coasts of Iran-Qatar-UAE, during the years 2010-2018, the concentration of PCB was in the 
range of 54-624 ng/g-pellet, and the highest contamination was observed near the coasts of Bushehr and Bandar Abbas. (Alidoust et al. 2021).

Pars gas field in the Persian Gulf is located $105 \mathrm{~km}$ from the nearest coast of Iran. The discovery and exploitation of this field has led to the establishment of oil, gas and petrochemical industries along with ancillary facilities in the region. Industrial development has also been accompanied by population growth and an increase in transportation services in the region.

The South Pars Industrial Zone is bounded on the south by the Persian Gulf and on the north by the mountains. Vast and pollutant industries, such as petrochemical complexes, gas refineries, power plants, storage tanks, and export wharves are located near the urban fabric (Samadi Kuchaksaraei et al. 2021).

Since the abovementioned industries and facilities can be the sources of production and release of PCBs to air, soil, and coasts, it is essential to investigate the destructive effects of sustainable organic compounds on health(Danesh et al. 2021) Arfaei Nia et al. were the first to measure PCB concentrations in coastal sediments of Assaluyeh To the best knowledge of the authors, there has not been similar studies conducted on the ecological hazards and source finding of PCBs in the air and coasts of the South Pars Industrial Zone (SPIZ).

On the other hand, it is necessary to re-measure and update the data on air, sediments, and seawater considering the passage of 5 years from a previous study on sediments and since a remarkable number of refineries, petrochemicals, and related facilities have been running in the area.

Measurements of PCB concentrations in seawater and air, ecological risk assessment, source identification, and determination of exchange in liquid-air/liquid-sediment phases were the innovations of this study which were done in SPIZ for the first time, the results of which can be a reference for further studies.

The five main objectives of this research are: 1) measuring the levels and profiling of PCBs attached to dust particles in the air, seawater, and coastal sediments of the region, 2) determining the origin of PCBs,

3) ecological hazard assessment of PCBs, 4) providing local distribution maps of PCBs, and 5) an investigation of the pollution transfer process between air-seawater and seawater-sediments.

\section{Materials And Methods}

\section{Study area}

The study area of SPIZ (Fig. 1) along the Persian Gulf coast in the south of Iran comprises a combination of light and heavy industries including 10 gas refineries, seven petrochemical complexes, electricity power plants, storage tanks, and export facilities. With geographical coordinates of 27.53438 to $27.41403 \mathrm{~N}$ and 52.25648 to $52.67028 \mathrm{E}$ and an approximate area of $521.5 \mathrm{~km} 2$, this area is connected to the Nayband National Park in the east and to Kangan city in the west. 
An area of $100 \mathrm{~km} 2$ of Assaluyeh city is located in the above area. The study area has been built by a combination of industrial and urban uses (Mahmoudi et al. 2020).

\section{Selection of the site and the sampling method}

A systematic sampling model was selected due to the low concentrations of PCBs which aimed at investigating the effects of SPIZ on the regional ecosystem and also factors such as sources of pollution, depth, and distance of human and industrial activities (Batley et al. 2016). Ten stations were selected for sampling sediments and water in the coastal area, and 10 stations were chosen for air sampling in the minimum possible distance in the coastal zone (Odabasi et al. 2017). According to the climatic conditions of the region, samples were taken in winter and summer 2019.

In the westernmost point of the study area, Shirino coastal village was selected as a control station as it was very distant from the related industries and activities. It is noteworthy that the village is used by oil, gas, and petrochemical companies for housing the employees (Ahmad et al. 2019Jalilisadrabad et al. 2020).

\section{Preparation of air samples}

Air was sampled randomly in each station from a height of $1.56 \mathrm{~m}$ above the ground by an SKC pump (model 9001-3011) with a flow of $20 \mathrm{~L} \mathrm{~min}^{-1}$ for $24 \mathrm{~h}$ every week in a three-month period. The sample size was in the range of 28-30 $\mathrm{m}^{3}$. Particulate matter was collected using polyurethane filters and an average weight of $15 \mathrm{~g}$. To avoid cross-contamination, separate forceps were used to remove each filter (Yang et al. 2021).

\section{Preparation of water and sediment samples}

To inactivate microorganisms in the water that could feed on volatile organic compounds and reduce their concentrations, hexane/dichloromethane solution in a ratio of 70 to $30(10 \mathrm{ml}$ in each sampling bottle depending on the volume of vessels) was injected into the solution in sampling bottles. Sediment samples were collected in sterile plant bags and aluminum foil. The temperature was stabilized using two cold boxes with a volume of 201 . Before sampling, the ice gels of each cold box were frozen at $-18{ }^{\circ} \mathrm{C}$ for 48 h. (Almeda et al. 2013).

Due to the measurement of PCBs, care was taken to use equipment and materials that did not contain chlorine compounds, and the glass was filled slowly due to the volatility of the compounds.

Sampling points were determined by the Global Positioning System (GPS) (Nozar et al. 2014). For sampling of sediments, Van Veen Grub type sampler with approximate dimensions of $55 \times 30 \times 22 \mathrm{~cm}$ (made of stainless steel) and mass of $5 \mathrm{~kg}$ was used. Water samples were taken from a depth of $5-10 \mathrm{~cm}$ of the sea by dark glass bottles. In each sampling, $10 \mathrm{I}$ and $500 \mathrm{~g}$ of water and sediments were sampled, respectively (Hoseyn Khezri et al. 2018). The depth of the sea was between 3 and $20 \mathrm{~m}$ at the time of sampling (Odabasi et al. 2017) 
The measured physicochemical parameters of water and sediments were salinity, temperature, $\mathrm{pH}$, and turbidity, and the evaluated physical parameters of air were wind speed, humidity, and air temperature.

\section{Laboratory tests}

The selected laboratory vessels were of the Pyrex type. Before transferring the samples to the laboratory, the vessels were thoroughly washed with $75^{\circ} \mathrm{C}$ water and dishwashing liquid. The dishes were then immersed in a dilute dishwashing liquid solution for 8 hours. The vessels were after that rinsed with $50{ }^{\circ} \mathrm{C}$ water at least 10 times and then placed in hexane-impregnated aluminum foil. Finally, the vessels were heated in an oven at $50^{\circ} \mathrm{C}$ for $4 \mathrm{~h}$ (Sari et al. 2020).

Filters containing airborne particles were immediately transferred to the laboratory and incubated at a temperature of $<4^{\circ} \mathrm{C}$. After washing the filters containing particulate matter, the compounds were extracted using a Soxhlet system with a capacity of $1000 \mathrm{ml}$ flask. Hexane was selected as the main solvent with a purity of $99.99 \%$ (Mercier et al. 2012).

The frozen precipitate was first crushed by a mortar and then sieved using a $250 \mu \mathrm{m}$ pore sieve, then; 20 $\mathrm{g}$ of the samples were transferred by fingers without using a hand. For this purpose, aluminum foil was wrapped around the fingers and the sample was transferred using forceps and also one $\mathrm{ml}$ of the standard internal solution of PCB 198 and PCB 29 with a concentration of 20ng / $\mathrm{ml}$ were added to the finger. The extraction was performed for 8 hours by adding some boiling stone and $250 \mathrm{ml}$ of hexane / dichloromethane solution (50:50 ratio). (Benson et al. 2020)

PCBs in seawater were extracted by the DLLME method. In the first step, $5 \mathrm{ml}$ of the sample solution was poured into a test tube with a conical end, followed by a quick addition of $500 \mu$ l of acetone with $10 \mu \mathrm{l}$ of Chloro benzene using a syringe with a capacity of $500 \mu$ to create a cloudy state in the sample. This was done to create a wide contact surface between the solvent range and the aqueous medium.

In the next step, the sample was centrifuged at $5000 \mathrm{rpm}$ for $2 \mathrm{~min}$. Chloro benzene droplets were then taken from the bottom of the test tube (Rezaei et al. 2008) The organic matter (OM) content was determined by the weighing method, through heating at $600^{\circ} \mathrm{C}$ for $4 \mathrm{~h}$ (Wang et al. 2011)

To prepare the standard peak, $1 \mathrm{ml}$ of internal standard solution was used instead of the sample. The Soxhlet-extracted sample was concentrated to a volume of $15 \mathrm{ml}$ by a rotary evaporator at $27^{\circ} \mathrm{C}$, dried over anhydrous sodium sulfate, and made to a volume of $1 \mathrm{ml}$ with nitrogen (Benson et al. 2020).

\section{Desulfurization using copper powder}

The copper powder was used for the removal of free sulfur and existing mercaptans. To do this, $20 \mathrm{~g}$ of copper powder was combined with concentrated hydrochloric acid in an Erlenmeyer in such a way to completely cover the surface of the copper powder. The Erlenmeyer was then shaken and transferred to an ultrasonic bath. This procedure was repeated after $10 \mathrm{~min}$. The acid was emptied on the copper 
surfaces, and fresh acid was added again to the copper surfaces. The acid was replaced by repetition for 4 times.

After the fourth step, the acid was replaced with distilled water, and the copper was shaken again and transferred to an ultrasonic bath for $10 \mathrm{~min}$. This procedure was repeated to neutralize the $\mathrm{pH}$ of the mixture. It was then washed with acetone and transferred to an ultrasonic bath, which was repeated 4 times.

The copper particles were then transferred to the hexane solvent. After adding copper to the samples, sulfur was removed from the sample by changing the copper color after $12 \mathrm{~h}$ (Pérez-Fernández et al. 2019Rezaee et al. 2006).

\section{Injection of PCB samples into a GC device}

By an automatic sampler, Samples were injected into a GC / MS Agilent-7890 B and a mass detector (5977 A MSD) with a DB-5MS chromatogram column to obtain the mass spectrum. The results were compared with a standard reference calibration. The temperature program (for PCB) first reached $150^{\circ} \mathrm{C}$, followed by 210,270 , and $280^{\circ} \mathrm{C}$ with slopes of 12,3 , and $20^{\circ} \mathrm{C}$ in three stages. The carrier gas was also helium (Wang et al. 2011)

\section{Quality control and guarantee}

The reliability of the observed results and quality control were examined by the following procedures. The tests were performed using devices with a valid calibration certificate approved by accredited authorities according to the standards of the Department of Environment of Iran. All sampling and testing instruments were washed with water, purified water, ACE, and PE.

An alternative standard solution with specific concentrations was prepared for PCBs and added to each sample and the blank sample to calculate the recovery efficiency before the extraction step. Each sample was repeated twice. The recovery efficiency for PCBs was $75.4 \%-115.2 \%$, and the obtained data were acceptable without the need for correction.

The accuracy of the analysis using the applied materials was ensured by preparing a blank sample whose composition was read below the limit of detection (LOD). Standard PCB solutions were used to construct GC/MS calibration curves with five calibration points at concentrations of $10,50,100,250$, and $500 \mathrm{ng} / \mathrm{ml}$. Linear responses $\left(r^{2}>0.999\right)$ were reported afterward. The LOD and limit of quantitation (LOQ) were measured by three times a signal-to-noise ratio (Sari et al. 2020) and consider $0.33,1$

\section{Statistical analysis}

Data were analyzed by IBM SPSS ver.22 and 2010 Microsoft Excel software. The calculated indices were standard deviation, mean, and median. The normality of data was verified using statistical tests such as Shapiro-Wilk. Non-parametric synonymous tests were used when data were highly dispersed (non- 
normal). The effect of seasons on data distribution was assessed using the one-way analysis of variance (ANOVA) at a significance level of 0.05 .

\section{Preparation of zonation maps}

Spatial distribution maps of pollutant concentrations were prepared by ArcGIS 10.2 software using exploratory geostatistics interpolation analysis of Kriging method.

\section{Ecological risk}

Two conventional methods were used to assess the ecological risk:

1. Calculation of ERI ecological risk index for seawater

The ecological risk assessment index in this formula is equal to the sum of the ecological risks $(E)$ of all PCB in a sample (Eq. 1).

$$
E R I=\sum E_{r}^{i}
$$

$E_{r}^{i}=T_{r}^{i} \cdot C_{f}^{i}$

$$
C_{f}^{i}=C_{0}^{i} / C_{n}^{i}
$$

In this formula, the number T is the toxicity factor, which equals 40 by default for PCBs. The $C_{f}$ number is the contamination factor obtained by dividing the concentration of a particular PCB by the reference dose or Cn equal to $0.01 \mathrm{mg} / \mathrm{L}$ or $10 \mathrm{ng} / \mathrm{g} . \mathrm{dw}$ For PCB numbers, ER numbers of $<40,40-70$, and $>70$ mean low, moderate, and high risks, respectively (Iwegbue et al. 2020).

\section{Sediment quality guidelines (SQGs)}

SQGs were widely used to assess sediment risk in marine environments with the development of biological effects database for sediments (BEDS). ERL and ERM indicate that the probability of biological effects is $<10 \%$ and $>50 \%$, respectively. Concentrations below ERL, between ERL and ERM, and above ERM indicate seldom, occasional, and frequent occurrence of adverse biological effects, respectively (Cao et al. 2020Li et al. 2017)

\section{Water and sediment exchange}

The exchange state of PAHs and PCBs in water and sediments is calculated and analyzed using the fugacity fraction (ff): $\mathrm{ff}=\frac{K_{o c}^{\prime}}{K_{O C}^{\prime}+K_{o c}}$, where $\left(K_{O C}\right)$ and $\left(K_{O C}^{\prime}\right)$ are the Organic carbon normalized partitioning coefficients and in situ sediment-water partitioning coefficient, respectively. $K_{O C}^{\prime}$ is obtained based on this equation: 
$K_{O C}^{\prime}=C_{S} /\left(c_{W} \times f_{O C}\right)$

Concentrations of sediment $\left(C_{s}\right)$ and water $\left(C_{w}\right)$ are obtained as and $\mathrm{ng} / \mathrm{L}$, andf ${ }_{O C}$ is the fraction of organic carbon, the relationship of which with the fraction of organic matter $\left(f_{O m}\right)$ is $f_{O C=f_{O m}} / 1.8$

The $K_{O C}$ ratio is an experimental value based on laboratory simulations, it was tried to use the numbers obtained in similar studies, including PCBs. If the ratio is not available, it can be predicted based on the $n$ octanol-water partition coefficient $\left(K_{\text {oW }}\right)$ (Zhao et al. 2021)

Based on the experimental results, is obtained by the following linear-logarithmic relationship: $\log K_{O C}=a \cdot \log K_{O W}+b$

In this study, the values of $a=1.04$ and $b=-0.61$ were used based on a similar study on PCBs (Zhang et al. 2013).

In the chemical partition of water and organic matter phases, $K_{O W}$ is a key parameter that can be extracted from sources such as the Handbook of Physical-Chemical Properties and Environmental Fate for Organic Chemicals/Mackay and the US EPA EPI Suite ${ }^{\text {TM }}$ which contains the properties of more than 40,000 chemicals.

The result of the abovementioned fraction is analyzed as:

$\mathrm{ff}<0.3$ Means the movement of pollutants from water to sediments creating a so-called sink state.

$0.3<\mathrm{ff}<0.7$ means that the pollutant is in an equilibrium state between the water and the sediment, and $0.7<\mathrm{ff}$ means that the pollutant moves toward seawater from sediments, with sediments playing a role as the second source of pollution spread in water.

\section{Source identification}

To analyze the source, the characteristics and share of environmental PCB sources were calculated using the Unmix EPA model.

In principle, the Unmix EPA model can be characterized by the following equation:

$X_{i j \equiv} \sum_{i} f_{i k} G_{k j}$, where $\mathrm{x}_{\mathrm{ij}}$ is the type of $\mathrm{i}$ concentration in sample $\mathrm{j}, \mathrm{f}_{\mathrm{ik}}$ is the species concentration in source $k$, and $G_{k j}$ is the share of source $k$ in sample $j$. The main logic of the aforementioned model is to create a chemical balance between the outputs of the sources received in the sample. The signal/noise index is one of the source acceptance criteria in the software and presents important items (e.g. stability error) in the final report. Information about this model is detailed in the Unmix6 EPA Principles and User Guide (EPA. 2007)

\section{Results And Discussion}




\section{Air}

In the cold season, the total concentrations of PCB were in the ranges of $3-3.63$ and $2.82-4.42 \mathrm{ng} / \mathrm{m}^{3}$ in urban and industrial areas, respectively. These numbers decrease significantly in the warm season. The highest concentration of PCB153 $\left(3.24 \mathrm{ng} / \mathrm{m}^{3}\right)$ was measured in the air adjacent to the industrial area. These values are higher than those reported in Dalian, China, and lower than those of the Aliaga Industrial Zone, Turkey.

Among homologs, the highest concentration $\left(3.24 \mathrm{ng} / \mathrm{m}^{3}\right)$ was recorded for Hexa-PCB in the vicinity of petrochemical complexes, and the highest percentages of low-chlorine PCB (49.45\% and $40 \%)$ were measured in stations 7 and 8 (residential areas), respectively.

The highest percentages of perchlorate compounds ( $84.77 \%$ and $87.07 \%)$ were estimated in the stations adjacent to petrochemical complexes and urban areas, respectively. The compounds were distributed uniformly based on the number of chlorides in the study area, and no significant difference was observed between values recorded close to industrial units and urban areas. The results are summarized in Table 1 and Fig. 2

Table 1

Statistical report of the concentration of PCB congeners in the study area inng ${ }_{P C B}$ / $M 3$

\begin{tabular}{|c|c|c|c|c|c|c|c|c|}
\hline \multirow[t]{2}{*}{ Component } & \multicolumn{4}{|c|}{ Industrial station } & \multicolumn{4}{|c|}{ Residential stations } \\
\hline & Range & Mean & Median & SD & Range & Mean & Median & SD \\
\hline РСВ 28 & $\begin{array}{l}0.18- \\
1.11\end{array}$ & 0.54 & 0.32 & 0.36 & $\begin{array}{l}0.23- \\
0.58\end{array}$ & 17.89 & 13.99 & 10.96 \\
\hline РСB 52 & $\begin{array}{l}0.17- \\
0.88\end{array}$ & 0.49 & 0.30 & 0.31 & $\begin{array}{l}0.22- \\
1.54\end{array}$ & 33.29 & 31.35 & 21.55 \\
\hline PCB 101 & $\begin{array}{l}0.21- \\
0.78\end{array}$ & 0.53 & 0.72 & 0.26 & $\begin{array}{l}0.48- \\
1.45\end{array}$ & 32.55 & 24.96 & 21.62 \\
\hline PCB 138 & ND-1.27 & 0.60 & 0.51 & 0.42 & ND-0.39 & 15.51 & 14.37 & 6.89 \\
\hline РCB 153 & $025-3.24$ & 1.17 & 0.78 & 1.06 & $\begin{array}{l}0.23- \\
0.52\end{array}$ & 9.48 & 7.72 & 9.42 \\
\hline PCB 194 & ND-0.36 & 0.19 & 0.22 & 0.12 & ND-0.88 & 15.20 & 12.31 & 13.99 \\
\hline РCB 195 & ND-0.35 & 0.22 & 0.25 & 0.12 & ND-1.33 & 21.15 & 12.25 & 25.52 \\
\hline$\sum P C B S$ & $\begin{array}{l}2.82- \\
4.42\end{array}$ & 3.72 & 3.81 & 0.54 & $3-3.63$ & 156.75 & 161.66 & 27.69 \\
\hline
\end{tabular}

\section{Seawater}

The test results of water samples were reported in $\mathrm{ppb}$ or $\mu \mathrm{g} / \mathrm{L}$. In table no.2 is shown the results obtained based on the type of compounds in terms of the range of variations (minimum/maximum, average, 
median, and standard deviation). The highest concentration of PCBs was observed in station 2 located near the outlet of export tanks of chemical products. Among PCBs, the highest pollutant concentrations belonged to PCB 101 (40.18 ppb) in winter and PCB194 (194 ppb) in summer. Figure 3 shows the spatial distribution of PCB compounds in seawater.

Table 2

Distribution of PCBs in seawater in cold and hot seasons according to the type of compound

\begin{tabular}{|c|c|c|c|c|c|c|c|c|}
\hline \multirow[t]{2}{*}{ Component } & \multicolumn{4}{|l|}{ Winter } & \multicolumn{4}{|l|}{ Summer } \\
\hline & Range & Mean & Median & SD & Range & Mean & Median & SD \\
\hline PCB18 & N.D & - & - & - & ND- 1.73 & 0.20 & 0.03 & 0.51 \\
\hline РСВ 31 & ND- 3.70 & 0.7 & 0.00 & 1.4 & ND- 1.21 & 0.29 & 0.12 & 0.35 \\
\hline РCB 44 & ND- 30.38 & 8.65 & 3.98 & 10.88 & ND- 1.04 & 0.18 & 0.04 & 0.31 \\
\hline PCB 52 & ND- 35.77 & 13.06 & 7.10 & 11.41 & ND- 0.54 & 0.11 & 0.00 & 0.21 \\
\hline PCB 101 & ND- 40.18 & 11.29 & 3.19 & 14.48 & ND- 1.45 & 0.22 & 0.08 & 0.41 \\
\hline PCB 141 & ND- 1.60 & 0.16 & 0.00 & 0.48 & ND & - & - & - \\
\hline РCB 149 & ND- 3.27 & 1.22 & 0.82 & 1.30 & ND & - & - & - \\
\hline РCB 138 & ND- 16.33 & 3.27 & 0.00 & 6.53 & ND- 0.81 & 0.14 & 0.05 & 0.24 \\
\hline РCB 153 & ND- 3.81 & 0.87 & 0.14 & 1.43 & ND- 4.91 & 0.95 & 0.25 & 1.53 \\
\hline РCB 189 & ND- 3.20 & 0.63 & 0.00 & 1.26 & ND & - & - & - \\
\hline PCB194 & ND & - & - & - & ND- 12.25 & 2.30 & 0.29 & 4.09 \\
\hline PCBs & ND- 135.68 & 39.85 & 16.62 & 48.21 & ND- 22.29 & 4.38 & 0.94 & 7.33 \\
\hline
\end{tabular}

\section{Sediments}

The test results of sediment samples were reported in $\mathrm{ppb}$ or $\mathrm{ng} / \mathrm{g}$ dry weight. Tables 3 summarizes the results obtained based on the type of compounds in terms of the range of variations (minimum/maximum, average, median, and standard deviation).PCB18 (43.6 ppb) in winter and PCB44 $(566 \mathrm{ppb})$ in summer reached the highest concentrations of PCBs. Among the stations, the highest concentration of PCBs was estimated in station 6 located near the outlets of refineries to the sea.

Examination of the results based on homologs of PCBs indicates the predominance of compounds with less chlorine content. The average decreased but the cumulative level of pollution increased compared to the results of a previous study. It seems that the pollution is distributed locally along with the formation of foci of contamination (Arfaeinia et al. 2017) Fig. 4 shows the spatial distribution of PCB compounds in the area sediments. 
Table 3

Distribution of concentration of PCB compounds in coastal sediment cold and hot seasons according to station number

\begin{tabular}{|lllllllll|}
\hline Component & Winter & \multicolumn{7}{c|}{ Summer } \\
\cline { 2 - 9 } & Range & Mean & Median & SD & Range & Mean & Median & SD \\
\hline PCB 18 & ND- 43.57 & 13.48 & 6.91 & 15.06 & ND-2.00 & 0.30 & 0.00 & 0.64 \\
\hline PCB 31 & ND & - & - & - & ND & - & - & - \\
\hline PCB 28 & ND-1.97 & 0.38 & 0.00 & 0.76 & ND & - & - & - \\
\hline PCB 44 & ND-10.85 & 4.47 & 4.52 & 4.17 & ND- & 56.60 & 0.00 & 169.80 \\
\hline PCB 52 & ND & - & - & - & ND-3.00 & 0.80 & 0.00 & 1.25 \\
\hline PCB 105 & ND-3.45 & 2.00 & 1.90 & 0.91 & ND-14.00 & 1.60 & 0.00 & 4.18 \\
\hline PCB 141 & ND & - & - & - & ND & - & - & - \\
\hline PCB 149 & ND & - & - & - & ND & - & - & - \\
\hline PCB 138 & ND-5.09 & 1.47 & 1.86 & 1.51 & ND & - & - & - \\
\hline PCB 151 & ND-5.26 & 1.76 & 1.80 & 1.76 & ND & - & - & - \\
\hline PCB 180 & ND-5.09 & 1.41 & 0.91 & 1.68 & ND-11.00 & 1.10 & 0.00 & 3.30 \\
\hline PCB 194 & ND & - & - & - & ND & - & - & - \\
\hline PCBs & 5.68- & 24.98 & 20.63 & 15.41 & ND- & 60.40 & 1.50 & 172.94 \\
\hline COntro & 54.42 & & & & 579.00 & & & \\
\hline
\end{tabular}

\section{Control station}

The results of the control station (Table 4) show much lower values than those of the other stations but they are more than the studies on similar areas in the Persian Gulf (Bahrain). Concentrations in air and sediments increase significantly with the change of seasons.

Table 4

Control station results

\begin{tabular}{|c|c|c|c|}
\hline \multirow[t]{3}{*}{ Ecological risk } & \multicolumn{2}{|c|}{ Concentration range } & \multirow[t]{2}{*}{ Media } \\
\hline & Summer & Winter & \\
\hline & ND & ND-1.45 ng/M3 & Air \\
\hline Low & ND-7.56 & ND- $6.45 \mu \mathrm{g} / \mathrm{L}$ & Seawater \\
\hline Low & ND- 2.00 & ND- 5.26 ng/g.dw & Coastal sediment \\
\hline
\end{tabular}


Based on the sedimentation rate of the study area in the Persian Gulf, the collected sediment sample can represent several years of introduced pollutants (Veerasingam et al. 2021); hence, the source of sea pollution was determined based on the results of sediments.

The results were modeled using Unmix EPA software. According to the analysis of the first source, highchlorine compounds (PCB105, PCB131, PCB151, and PCB180) were predominant at $68.1 \%$. These compounds contain a high percentage of commercial compounds, PCB1254 and PCB1260, which are used in various applications such as power converters, gas distribution turbines, hydraulic fluids, adhesives, tires, heat transfer systems, wax diluents, and carbonless papers (Information, 2021).

This source can be attributed to industrial units such as power plants and industrial wastewater treatment units, and petrochemical complexes and refineries. In source 2 , the majority of pollutants (93.4\%) belonged to low-chlorine compounds (PCB18, PCB28, and PCB44), which make up a high percentage of arcolor1016 and are mostly used in capacitors and electrical insulators.

The highest concentrations of low-chlorine PCB compounds were detected in station 3 located near the outlet of petrochemical complexes. These results deserve consideration given the extensive construction of the abovementioned complexes (Dumanoglu et al. 2017). Source 2 can be considered a place for the disposal of electrical waste. The results are summarized in Table 5 and Fig. 5.

Table 5. Sources compositions

\begin{tabular}{lll} 
Species & Source 1 & Source 2 \\
\hline PCB 18 & 1.690 & 11.900 \\
\hline PCB 28 & -0.024 & 0.530 \\
\hline PCB 44 & 1.030 & 3.080 \\
\hline PCB 105 & 1.200 & 0.595 \\
\hline PCB 138 & 1.530 & -0.010 \\
\hline PCB 151 & 1.500 & 0.496 \\
\hline PCB 180 & 1.590 & -0.027 \\
\hline PCBs & 8.440 & 16.500
\end{tabular}

\section{Seawater ecological risk}

The ecological risk of each station was determined using the concentrations of PCBs in water samples by relationships 1, 2, and 3. The calculated risk of the area ranged from 23 to 218 . High, moderate, and low risks were found in six, three, and one stations, respectively, with an average risk of 100 . The highest level of risk was observed adjacent to the outlets of industrial companies to the sea, which is higher than that measured around the Larak Island in the Persian Gulf. 
SQGs

According to the indicators defined in the instructions, the ecological risk level of sediments was in the medium range in station 6 , and the rest of the sampled stations were evaluated in the low range. The seabed results currently show less pollution than those of seawater. The ecological risk is slightly lower in the northern Persian Gulf and is fairly higher than that of the shores of Bahrain on the shores of the Persian Gulf (Table 6).

Table 6

The component ERL and ERM for PCBs

\begin{tabular}{|lcccc|}
\hline Component & ERL & ERM & \multicolumn{2}{l|}{ Current study } \\
\cline { 4 - 5 } & & & Min. & Max. \\
\hline Total PCBs & 0.023 & 0.18 & 0 & 0.0597 \\
\hline ERL - Effect Range Low; ERM - Effect Range & Median Long (Burton. 2002) \\
\hline
\end{tabular}

\section{The exchange flow of the seawater/sediment interface}

The fugacity index was calculated and reported at each station using the results of the concentrations of PCBs in sediments and seawater as well as related formulas. Based on these results, low-chlorine compounds (e.g. PCB52 and PCB44) mostly precipitated from seawater to sediments, and the seabed played the role of a sink for these compounds. Medium-chlorine compounds (e.g. PCB 105) were in equilibrium in some stations. Heavier compounds (e.g. PCB180 and PCB194) often entered seawater from sediments, and sediments are actually the secondary source of seawater pollution with compounds having more chlorine content.

\section{Similar studies}

A better understanding of pollution in the study area is obtained by examining the records of studies on PCBs in coastal industrial areas worldwide, particularly those with similar climatic-industrial conditions. As shown in Table 7, the maximum concentration increased relative to the previous study in the area (sediments), but a decrease in the average indicates the formation of local pollution masses.

The concentration increased compared to those of the northern Persian Gulf, the coast of the Persian Gulf near Bahrain, and mangrove forests near the Assaluyeh region. This pollution can endanger the ecosystem of mangrove forests. The obtained concentration is lower than that of a similar coastal industrial zone in Turkey. The prevailing transfer process from the seawater phase to air in the vicinity of the outlets of industrial complexes is similar to the mentioned industrial zone. 
Table 7

Similar studies

\begin{tabular}{|c|c|c|c|c|}
\hline Reference & Ecological risk & Concentration range & Environment & Study area \\
\hline \multirow{2}{*}{$\begin{array}{l}\text { (Arfaeinia } \\
\text { et al. } \\
\text { 2017) }\end{array}$} & & Max:74062pg/g & \multirow[t]{2}{*}{ sediment } & \multirow[t]{2}{*}{ Assaluyeh Iran } \\
\hline & & $\begin{array}{l}\text { Industrial Ave. } 514.32 \text { urban } \\
\text { Ave. } 144.67 \mathrm{pg} / \mathrm{g} . \mathrm{dw}\end{array}$ & & \\
\hline \multirow{2}{*}{$\begin{array}{l}\text { (Nozar et } \\
\text { al. 2014) }\end{array}$} & $\% 10.3>$ ERL & \multirow[t]{2}{*}{ sediment: $2.5-462(\mathrm{ng} / \mathrm{g} . \mathrm{dw})$} & \multirow[t]{2}{*}{ sediment } & \multirow{2}{*}{$\begin{array}{l}\text { North Persian } \\
\text { Gulf }\end{array}$} \\
\hline & $\% 2.9>$ ERM & & & \\
\hline \multirow{2}{*}{$\begin{array}{l}\text { (Ranjbar } \\
\text { Jafarabadi } \\
\text { et al. } \\
\text { 2019) }\end{array}$} & \multirow{2}{*}{$\begin{array}{l}\text { Toxicity } \\
\text { indicators } \\
\text { within the } \\
\text { permissible } \\
\text { level (WHO) }\end{array}$} & Seawater:0.97-3.1ng/L & \multirow{2}{*}{$\begin{array}{l}\text { sediment } \\
\text { \&seawater }\end{array}$} & \multirow{2}{*}{$\begin{array}{l}\text { Around Lark } \\
\text { Island - Iran }\end{array}$} \\
\hline & & Sediment:2.95-7.95ng/g.dw & & \\
\hline \multirow{3}{*}{$\begin{array}{l}\text { (Odabasi } \\
\text { et al. } \\
\text { 2017) }\end{array}$} & \multirow[t]{3}{*}{-} & sediment:2.7-2450(ng/g.dw) & \multirow{3}{*}{$\begin{array}{l}\text { Air\& } \\
\text { sediment } \\
\text { and } \\
\text { seawater }\end{array}$} & \multirow{3}{*}{$\begin{array}{l}\text { Aliaga industrial } \\
\text { region, Turkey }\end{array}$} \\
\hline & & seawater:880-50829(pg/L) & & \\
\hline & & air:104-20083pg/M3 & & \\
\hline \multirow{2}{*}{$\begin{array}{l}\text { (Behrooz } \\
\text { et al. } \\
\text { 2009) }\end{array}$} & \multirow[t]{2}{*}{-} & Seawater:8-375ng/L & \multirow{2}{*}{$\begin{array}{l}\text { Seawater\& } \\
\text { sediment }\end{array}$} & \multirow{2}{*}{$\begin{array}{l}\text { Southwest } \\
\text { Persian Gulf-Iran } \\
2009\end{array}$} \\
\hline & & Sediment:3.4-50.2 $\mu \mathrm{g} / \mathrm{g} . \mathrm{dw}$ & & \\
\hline $\begin{array}{l}\text { (Bersuder } \\
\text { et al. } \\
2020 \text { ) }\end{array}$ & $\begin{array}{l}\text { According to } \\
\text { the SQGs index } \\
\text { was low }\end{array}$ & $\begin{array}{l}\text { The highest concentration } \\
(0.881 \mathrm{ng} / \mathrm{g} . \mathrm{dw}) \text { was } \\
\text { observed in the vicinity of } \\
\text { refinery output }\end{array}$ & sediments & $\begin{array}{l}\text { Bahrain-Persian } \\
\text { Gulf coast }\end{array}$ \\
\hline \multirow{2}{*}{$\begin{array}{l}\text { (Alidoust } \\
\text { et al. } \\
\text { 2021) }\end{array}$} & \multirow[t]{2}{*}{-} & 54-624ng/g Pellet & \multirow{2}{*}{$\begin{array}{l}\text { Plastic resin } \\
\text { pellets } \\
\text { (plastic } \\
\text { waste) }\end{array}$} & \multirow{2}{*}{$\begin{array}{l}\text { Persian Gulf } \\
\text { Coasts (Iran, } \\
\text { Qatar and United } \\
\text { Arab Emirates) } \\
2010-2018\end{array}$} \\
\hline & & $\begin{array}{l}\text { The highest concentration was } \\
\text { observed in the vicinity of } \\
\text { Bushehr and Bandar Abbas } \\
\text { industrial cities }\end{array}$ & & \\
\hline \multirow{2}{*}{$\begin{array}{l}\text { (Montuori } \\
\text { et al. } \\
2020 \text { ) }\end{array}$} & & Water:4.1-48ng/L & \multirow{2}{*}{$\begin{array}{l}\text { water } \\
\text { sediment }\end{array}$} & \multirow{2}{*}{$\begin{array}{l}\text { Volturno River in } \\
\text { southern Italy } \\
2017-2018\end{array}$} \\
\hline & & Sediment:4.3-64.3ng/g.dw & & \\
\hline $\begin{array}{l}\text { (Zhong et } \\
\text { al. 2020) }\end{array}$ & Low & 106.7 to 270.0 pg./g.dw & sediment & $\begin{array}{l}\text { Liaohe Estuary } \\
\text { china }\end{array}$ \\
\hline
\end{tabular}

\section{Conclusion And Recommendations}

Based on the obtained data, the range of PCB concentrations in the marine sediments, water and air particulate matter, were 107.33-172.92 ng/g.dw, ND-135.68 $\mu \mathrm{g} / \mathrm{L}$, and ND-4.4 ng/m³ , respectively. Most of these concentrations were measured near the refineries, petrochemical industries, and oil export facilities, 
indicating the impacts of these industries on the pollution. This level of pollution increased significantly in winter.

The concentrations increased compared to studies from the northern Persian Gulf, Bahrain coasts, and mangrove forests near the study area. The sources of these compounds were electrical waste, their storage sites, power generation units, and wastewater treatment units. Different conditions were found in the study of seawater and sediment exchange so that heavier compounds with more chlorine moved from sediments to the seawater and the seabed played the role of a secondary source of sea pollution.

Lighter compounds with less chlorine moved to sediments from the seawater, and the seabed acted as a sink for these compounds. Given the mentioned exchange conditions, seawater seems to be the main source of pollution in the study area, and a part of the pollutant enters the air and the other part precipitates in the seabed; these conditions are intensified by such phenomena as sunlight, windstorms, and precipitation.

The ecological risk of seawater was assessed in high and polluted conditions, while better conditions currently exist in sediments with a low-medium range of risk. The observed role of seabed in precipitating part of the pollution suggests the very high probability of increasing the concentration of PCBs and the related ecological risk level in sediments.

It is suggested to continuously monitor and adopt engineering and management measures to improve and prevent the spread of pollution and perform complementary measurements on water and sediments of mangrove forests and native aquatic fish used by local people. Since the pollutant concentrations are used in the gas phase, it is recommended to use passive sampling methods in air sampling to investigate the exchange conditions.

\section{Declarations}

\section{Author contribution}

Fazel Amiri and Tayebeh Tabatabaie: conceptualization, methodology, writing-reviewing and editing. Alireza Ghadrshenas: sample preparation and chemical analysis. Abdul Rahim Pazira: writing-reviewing, and editing.

\section{Acknowledgments}

A. Ghadrshenas acknowledges support from the Islamic Azad University, Branch Bushehr in the College of Environmental Engineering.

\section{Conflicts of Interest}

The authors declare that they have no known competing financial interests or personal relationships that could have appeared to influence the work reported in this paper. 


\section{Data Availability}

Some or all data, models that support the findings of this study are available from the corresponding author upon reasonable request.

\section{References}

1. Aghadadashi V, Neyestani MR, Mehdinia A, Riyahi Bakhtiari A, Molaei S, Farhangi M, Gerivani H (2019) Spatial distribution and vertical profile of heavy metals in marine sediments around Iran's special economic energy zone; Arsenic as an enriched contaminant. Mar Pollut Bull 138:437-450. doi:10.1016/j.marpolbul.2018.11.033

2. Ahmad T, Esmaili A, Nader B (2019) Investigation of gaseous pollutants in residential-industrial area: Ambient levels, temporal variation and health risk assessment. J Air Pollution Health 4(2). doi:10.18502/japh.v4i2.1236

3. Alidoust M, Yeo GB, Mizukawa K, Takada H (2021) Monitoring of polycyclic aromatic hydrocarbons, hopanes, and polychlorinated biphenyls in the Persian Gulf in plastic resin pellets. Mar Pollut Bull 165:112052

4. Almeda R, Wambaugh Z, Wang Z, Hyatt C, Liu Z, Buskey EJ (2013) Interactions between zooplankton and crude oil: toxic effects and bioaccumulation of polycyclic aromatic hydrocarbons.PLOS ONE, 8(6), e67212

5. Arfaeinia H, Asadgol Z, Ahmadi E, Seifı M, Moradi M, Dobaradaran S (2017) Characteristics, distribution and sources of polychlorinated biphenyls (PCBs) in coastal sediments from the heavily industrialized area of Asalouyeh, Iran. Water Sci Technol 76(12):3340-3350. doi:10.2166/wst.2017.500

6. Batley G, Simpson S (2016) Chapter 2. Sediment sampling, sample preparation and general analysis. CSIRO Publishing, Clayton South, Vic

7. Behrooz RD, Esmaili-Sari A, Ghasempouri SM, Bahramifar N, Covaci A (2009) Organochlorine pesticide and polychlorinated biphenyl residues in feathers of birds from different trophic levels of South-West Iran. Environ Int 35(2):285-290

8. Benson NU, Fred-Ahmadu OH, Ekett SI, Basil MO, Adebowale AD, Adewale AG, Ayejuyo 00 (2020) Occurrence, depth distribution and risk assessment of PAHs and PCBs in sediment cores of Lagos lagoon, Nigeria. Reg Stud Mar Sci 37:101335. doi:10.1016/j.rsma.2020.101335

9. Bersuder P, Smith A, Hynes C, Warford L, Barber J, Losada S, Le Quesne W (2020) Baseline survey of marine sediments collected from the Kingdom of Bahrain: PAHs, PCBs, organochlorine pesticides, perfluoroalkyl substances, dioxins, brominated flame retardants and metal contamination. Mar Pollut Bull 161:111734

10. Burton JGA (2002) Sediment quality criteria in use around the world. Limnology 3(2):65-76. doi:10.1007/s102010200008 
11. Cao Y, Xin M, Wang B, Lin C, Liu X, He M, Lu S (2020) Spatiotemporal distribution, source, and ecological risk of polycyclic aromatic hydrocarbons (PAHs) in the urbanized semi-enclosed Jiaozhou Bay, China. Sci Total Environ 717:137224. doi:10.1016/j.scitotenv.2020.137224

12. Danesh G, Monavari SM, Omrani GA, Karbasi A, Farsad F (2021) Detection of suitable areas for waste disposal of petrochemical industries using integrated methods based on geographic information system. Arab J Geosci 14(14):1-12

13. Dumanoglu Y, Gaga EO, Gungormus E, Sofuoglu SC, Odabasi M (2017) Spatial and seasonal variations, sources, air-soil exchange, and carcinogenic risk assessment for PAHs and PCBs in air and soil of Kutahya, Turkey, the province of thermal power plants. Sci Total Environ 580:920-935. doi:https://doi.org/10.1016/j.scitotenv.2016.12.040

14. EPA U Learn about Polychlorinated Biphenyls (PCBs). Retrieved from https://www.epa.gov/pcbs/learn-about-polychlorinated-biphenyls-pcbs

15. EPA U (2007) EPA Unmix 6.0 Fundamentals \& User Guide Retrieved from https://www.epa.gov/sites/default/files/2020-05/documents/unmix-6-user-manual.pdf

16. Erickson MD, Kaley RG (2011) Applications of polychlorinated biphenyls. Environ Sci Pollut Res 18(2):135-151. doi:10.1007/s11356-010-0392-1

17. Farrington JW (2020) Need to update human health risk assessment protocols for polycyclic aromatic hydrocarbons in seafood after oil spills. Mar Pollut Bull 150:110744

18. Hoseyn Khezri P, Hatami Manesh M, Haghshenas A, Mirzaei M, Arbabi M, Mohammadi Bardkashki B (2018) Source Identification and Ecological Risk Assessment of Polycyclic Aromatic Hydrocarbons in Surface Sediments)Case Study: Pars Special Economic Energy Zone. J Mazandaran Univ Med Sci 28(160):56-75

19. Iwegbue CMA, Bebenimibo E, Tesi GO, Egobueze FE, Martincigh BS (2020) Spatial characteristics and risk assessment of polychlorinated biphenyls in surficial sediments around crude oil production facilities in the Escravos River Basin, Niger Delta, Nigeria. Mar Pollut Bull 159:111462. doi:https://doi.org/10.1016/j.marpolbul.2020.111462

20. Jalilisadrabad s, Zabetian Targhi E (2020) Investigating the Location of Organizational Housing on the Outskirts of Cities (Study Sample: Accommodation of Bandar Abbas gas Condensate Refinery Staff). NAQSHEJAHAN, 10(1 \#r001480), -

21. Li Y, Liu X, Liu M, Li X, Wang Q, Zhu J, Qadeer A (2017) Distribution, sources and ecological risk of polycyclic aromatic hydrocarbons in the estuarine-coastal sediments in the East China Sea. Environ Sci Process Impacts 19(4):561-569. doi:10.1039/c7em00016b

22. Löf M, Sundelin B, Bandh C, Gorokhova E (2016) Embryo aberrations in the amphipod Monoporeia affinis as indicators of toxic pollutants in sediments: A field evaluation. Ecol Ind 60:18-30. doi:https://doi.org/10.1016/j.ecolind.2015.05.058

23. Mahmoudi M, Pourebrahim S, Danehkar A, Moeinaddini M, Ziyarati MT (2020) Scenario-based planning for reduction of emitted $\mathrm{CO} 2$ from the Pars Special Economic Energy Zone (PSEEZ) of Iran. Environ Monit Assess 192(9):592. doi:10.1007/s10661-020-08553-2 
24. Maung R, Pellow DN (2021) Environmental Justice. Handbook of Environmental Sociology. Springer, pp 35-52

25. Mercier F, Glorennec P, Blanchard O, Le Bot B (2012) Analysis of semi-volatile organic compounds in indoor suspended particulate matter by thermal desorption coupled with gas chromatography/mass spectrometry. J Chromatogr A 1254:107-114

26. Montuori P, De Rosa E, Sarnacchiaro P, Di Duca F, Provvisiero DP, Nardone A, Triassi M (2020) Polychlorinated biphenyls and organochlorine pesticides in water and sediment from Volturno River, Southern Italy: occurrence, distribution and risk assessment. Environ Sci Europe 32(1):123. doi:10.1186/s12302-020-00408-4

27. Nozar SLM, Ismail WR, Zakaria MP (2014) Distribution, Sources Identification, and Ecological Risk of PAHs and PCBs in Coastal Surface Sediments from the Northern Persian Gulf. Hum Ecol Risk Assessment: Int J 20(6):1507-1520. doi:10.1080/10807039.2014.884410

28. Odabasi M, Dumanoglu Y, Kara M, Altiok H, Elbir T, Bayram A (2017) Spatial variation of PAHs and PCBs in coastal air, seawater, and sediments in a heavily industrialized region. Environ Sci Pollut Res Int 24(15):13749-13759. doi:10.1007/s11356-017-8991-8

29. Pérez-Fernández B, Viñas L, Bargiela J (2019) New values to assess polycyclic aromatic hydrocarbons pollution: Proposed background concentrations in marine sediment cores from the Atlantic Spanish Coast. Ecol Ind 101:702-709. doi:https://doi.org/10.1016/j.ecolind.2019.01.075

30. Ranjbar Jafarabadi A, Riyahi Bakhtiari A, Mitra S, Maisano M, Cappello T, Jadot C (2019) First polychlorinated biphenyls (PCBs) monitoring in seawater, surface sediments and marine fish communities of the Persian Gulf: Distribution, levels, congener profile and health risk assessment. Environ Pollut 253:78-88. doi:https://doi.org/10.1016/j.envpol.2019.07.023

31. Rezaee M, Assadi Y, Milani Hosseini M-R, Aghaee E, Ahmadi F, Berijani S (2006) Determination of organic compounds in water using dispersive liquid-liquid microextraction. J Chromatogr $A$ 1116(1):1-9. doi:https://doi.org/10.1016/j.chroma.2006.03.007

32. Rezaei F, Bidari A, Birjandi AP, Hosseini MRM, Assadi Y (2008) Development of a dispersive liquidliquid microextraction method for the determination of polychlorinated biphenyls in water. $\mathrm{J}$ Hazard Mater 158(2-3):621-627

33. Sakizadeh M (2020) Spatial distribution and source identification together with environmental health risk assessment of PAHs along the coastal zones of the USA. Environ Geochem Health 42(10):33333350

34. Samadi Kuchaksaraei B, Danehkar A, Fatemi SMR, Jozi SA, Ramezani-Fard E (2021) An investigation on the human impact intensity on the selected ecoregions of coastal areas of Hormozgan Province, Persian Gulf, Strait of Hormuz, South of Iran. Environment, Development \& Sustainability, 23(4)

35. Sari MF, Esen F, Aguila CD, Kurt Karakus PB (2020) Passive sampler derived polychlorinated biphenyls (PCBs) in indoor and outdoor air in Bursa, Turkey: Levels and an assessment of human exposure via inhalation. Atmospheric Pollution Research 11(6):71-80. doi:10.1016/j.apr.2020.03.001 
36. Veerasingam S, Vethamony P, Aboobacker VM, Giraldes AE, Dib S, Al-Khayat JA (2021) Factors influencing the vertical distribution of microplastics in the beach sediments around the Ras Rakan Island, Qatar.Environmental Science and Pollution Research,1-10

37. Wang W, Huang M-j, Kang Y, Wang H-s, Leung AOW, Cheung KC, Wong MH (2011) Polycyclic aromatic hydrocarbons (PAHs) in urban surface dust of Guangzhou, China: Status, sources and human health risk assessment. Sci Total Environ 409(21):4519-4527.

doi:https://doi.org/10.1016/j.scitotenv.2011.07.030

38. Yang L, Zhang X, Xing W, Zhou Q, Zhang L, Wu Q, Tang N (2021) Yearly variation in characteristics and health risk of polycyclic aromatic hydrocarbons and nitro-PAHs in urban shanghai from 20102018. J Environ Sci (China) 99:72-79. doi:10.1016/j.jes.2020.06.017

39. Zahed MA, Bidhendi N, Pardakhti G, Esmaili-Sari A, Mohajeri S (2009) Determination of polychlorinated biphenyl congeners in water and sediment in North West Persian Gulf, Iran. Bull Environ Contam Toxicol 83(6):899-902. doi:10.1007/s00128-009-9874-6

40. Zhang F-L, Yang X-J, Xue X-L, Tao X-Q, Lu G-N, Dang Z (2013) Estimation of Octanol/Water Partition Coefficients of Polychlorinated Biphenyls by Using Quantum Chemical Descriptors and Partial Least Squares. Journal of Chemistry, 2013, 740548. doi:10.1155/2013/740548

41. Zhao Z, Gong X, Zhang L, Jin M, Cai Y, Wang X (2021) Riverine transport and water-sediment exchange of polycyclic aromatic hydrocarbons (PAHs) along the middle-lower Yangtze River, China. J Hazard Mater 403:123973. doi:https://doi.org/10.1016/j.jhazmat.2020.123973

42. Zhong T, Niu N, Li X, Zhang D, Zou L, Yao S (2020) Distribution, composition profiles, source identification and potential risk assessment of Polychlorinated Biphenyls (PCBs) and Dechlorane Plus (DP) in sediments from Liaohe Estuary. Reg Stud Mar Sci 36:101291. doi:10.1016/j.rsma.2020.101291

\section{Figures}




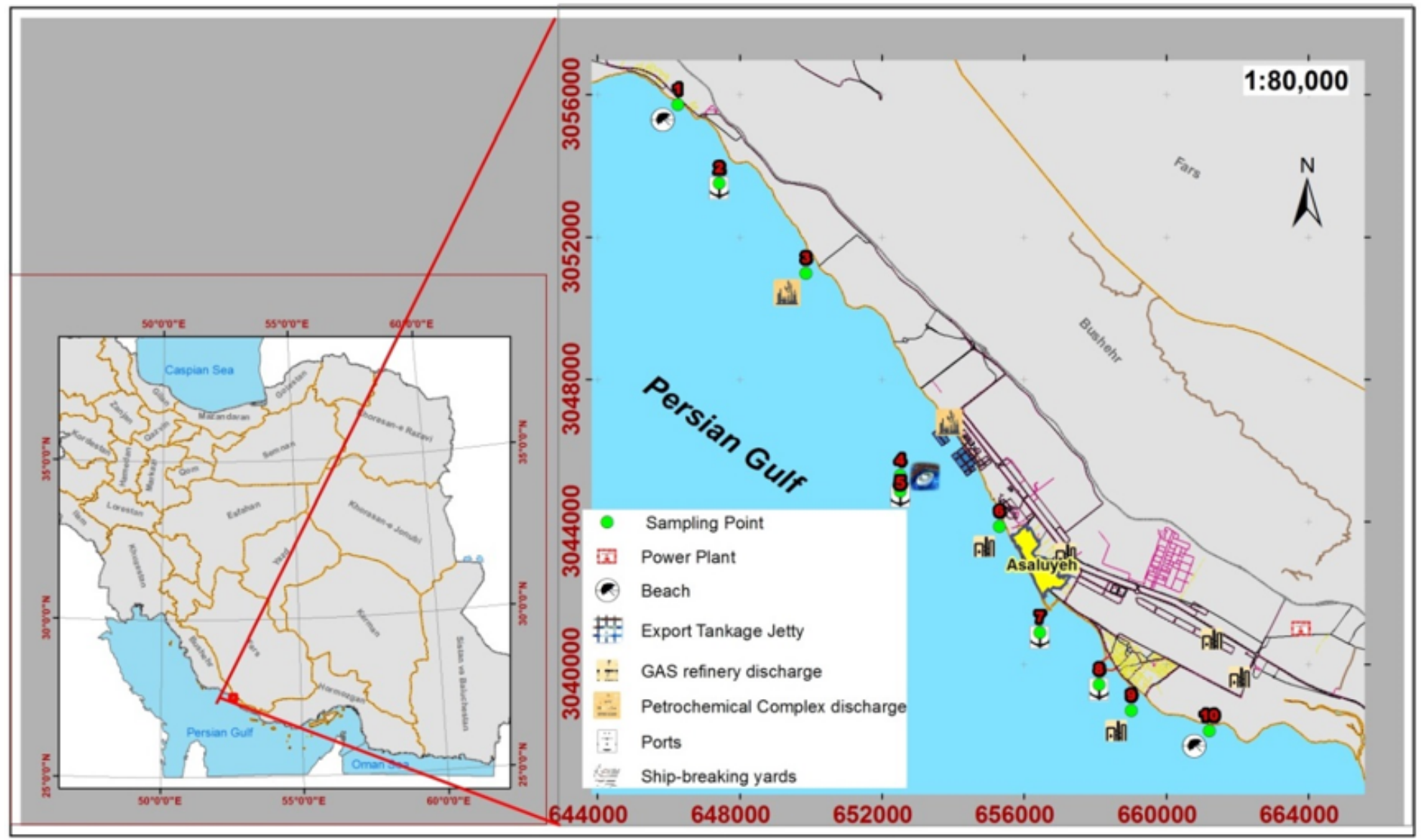

Figure 1

Study area (South Pars Industrial Zone) 


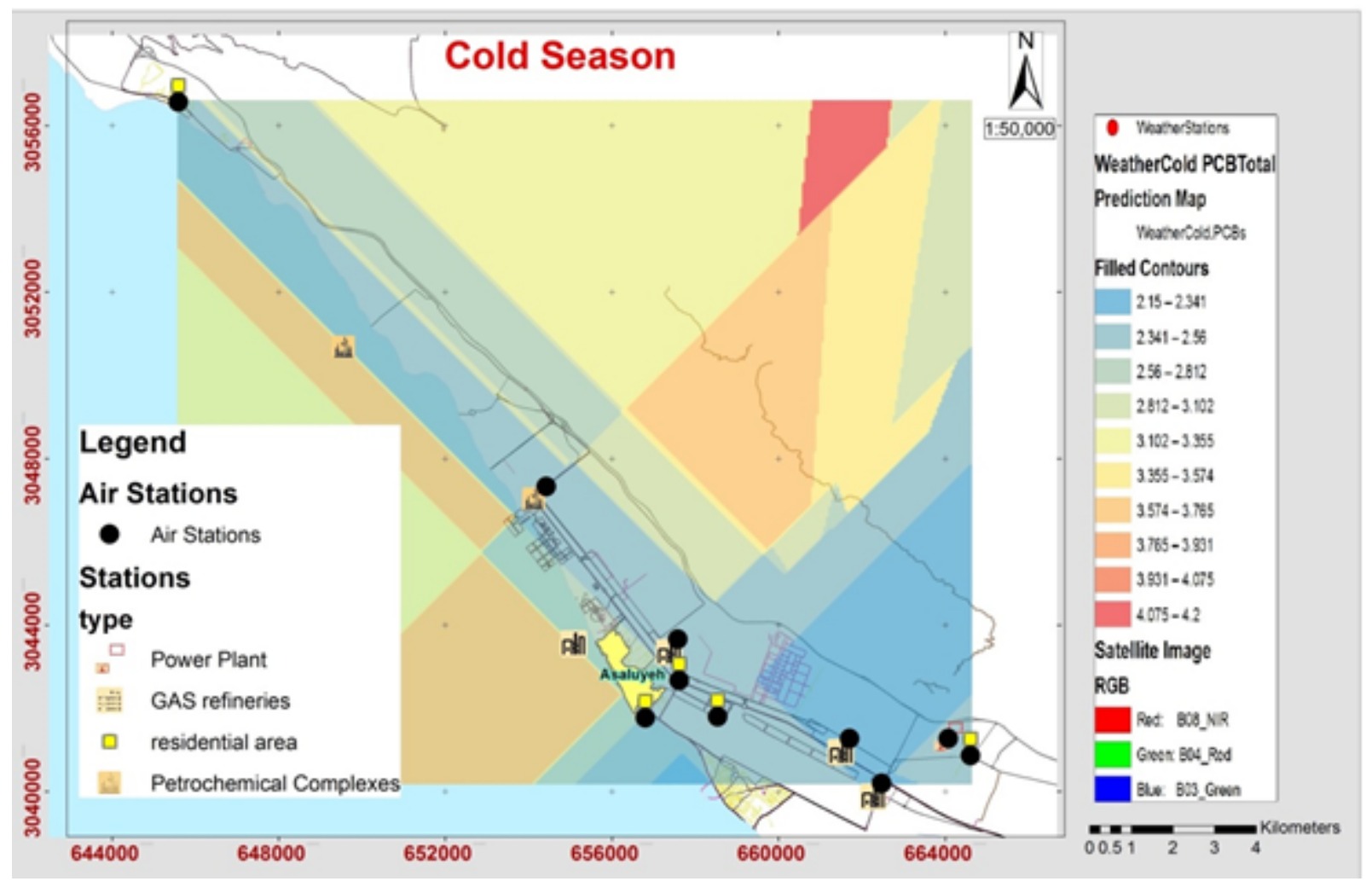

Figure 2

Distribution of PCBs in the air of the cold season study area 


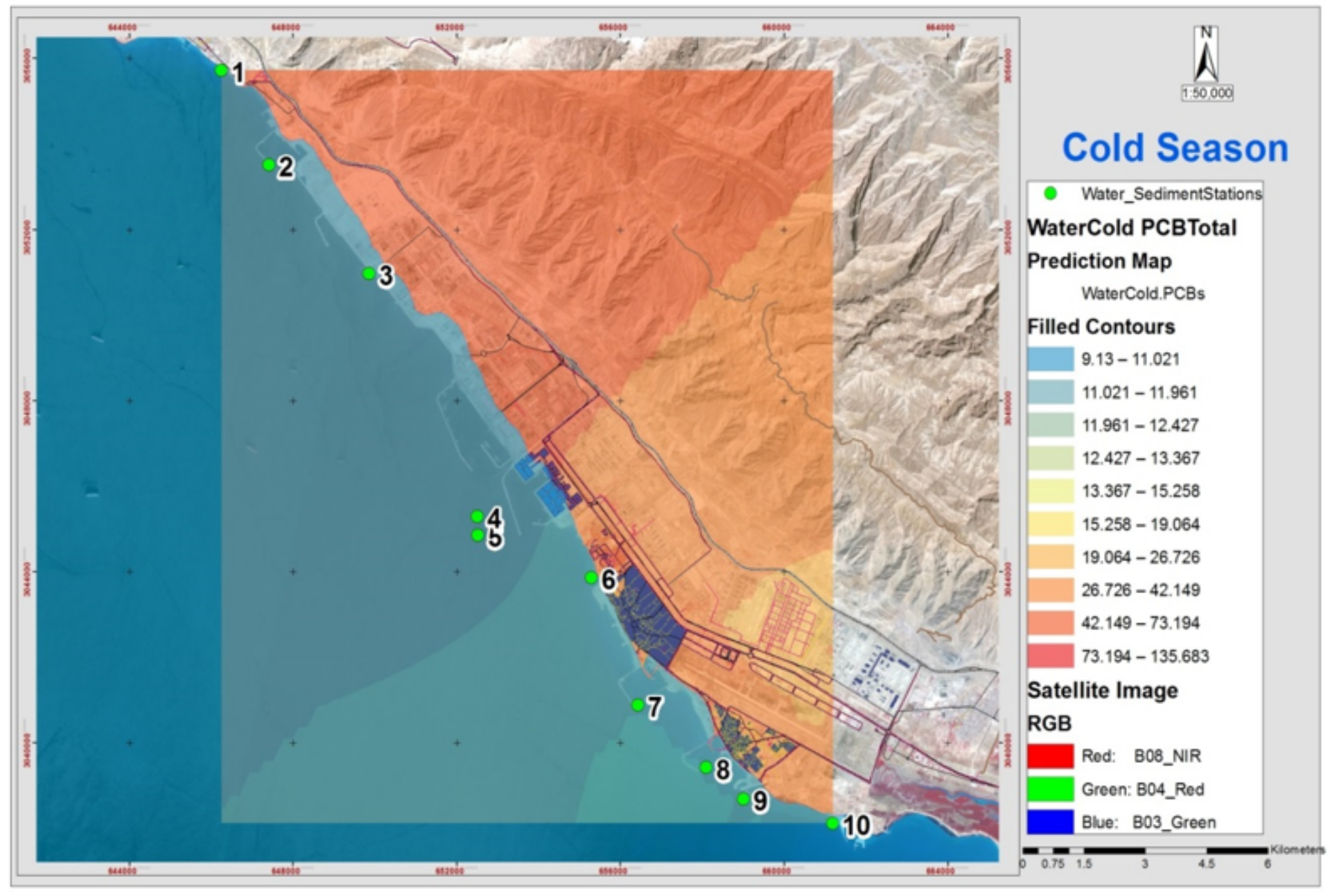

Figure 3

Spatial distribution of seawater PCBs in the study area 


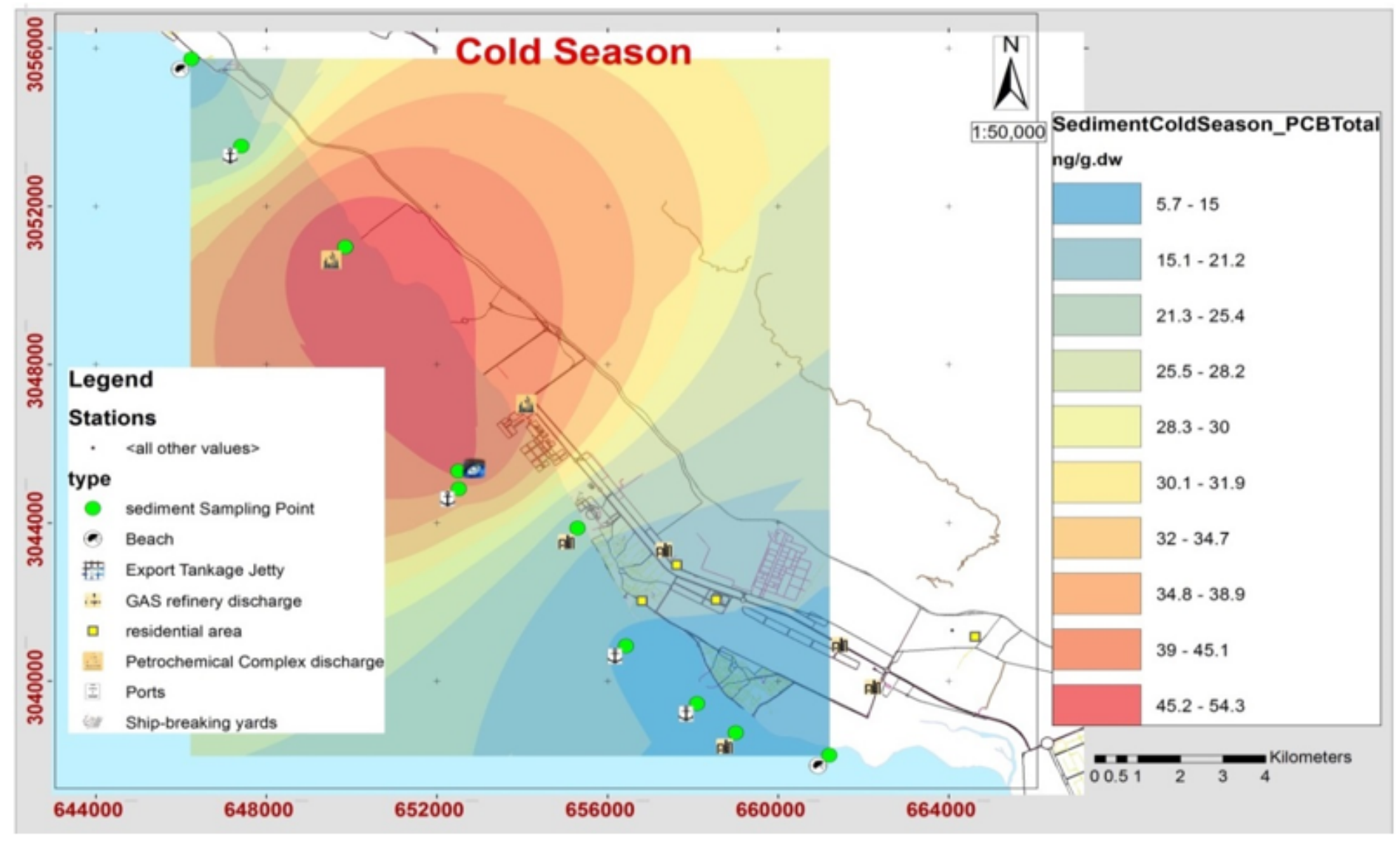

\section{Figure 4}

Spatial distribution of PCBs in the study area sediment

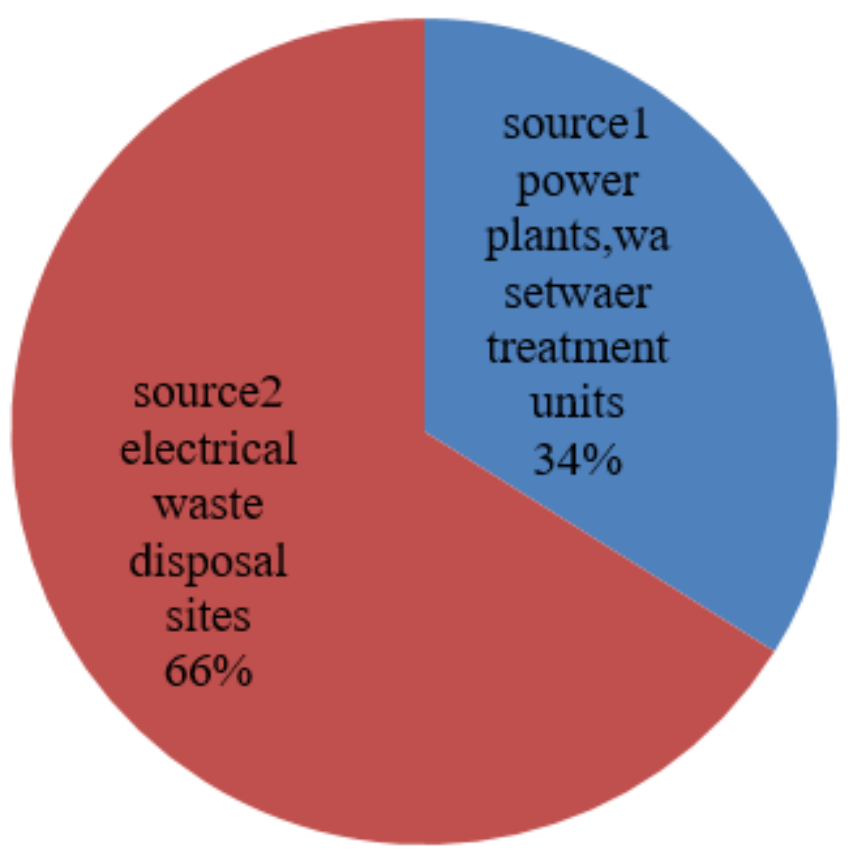

Figure 5 


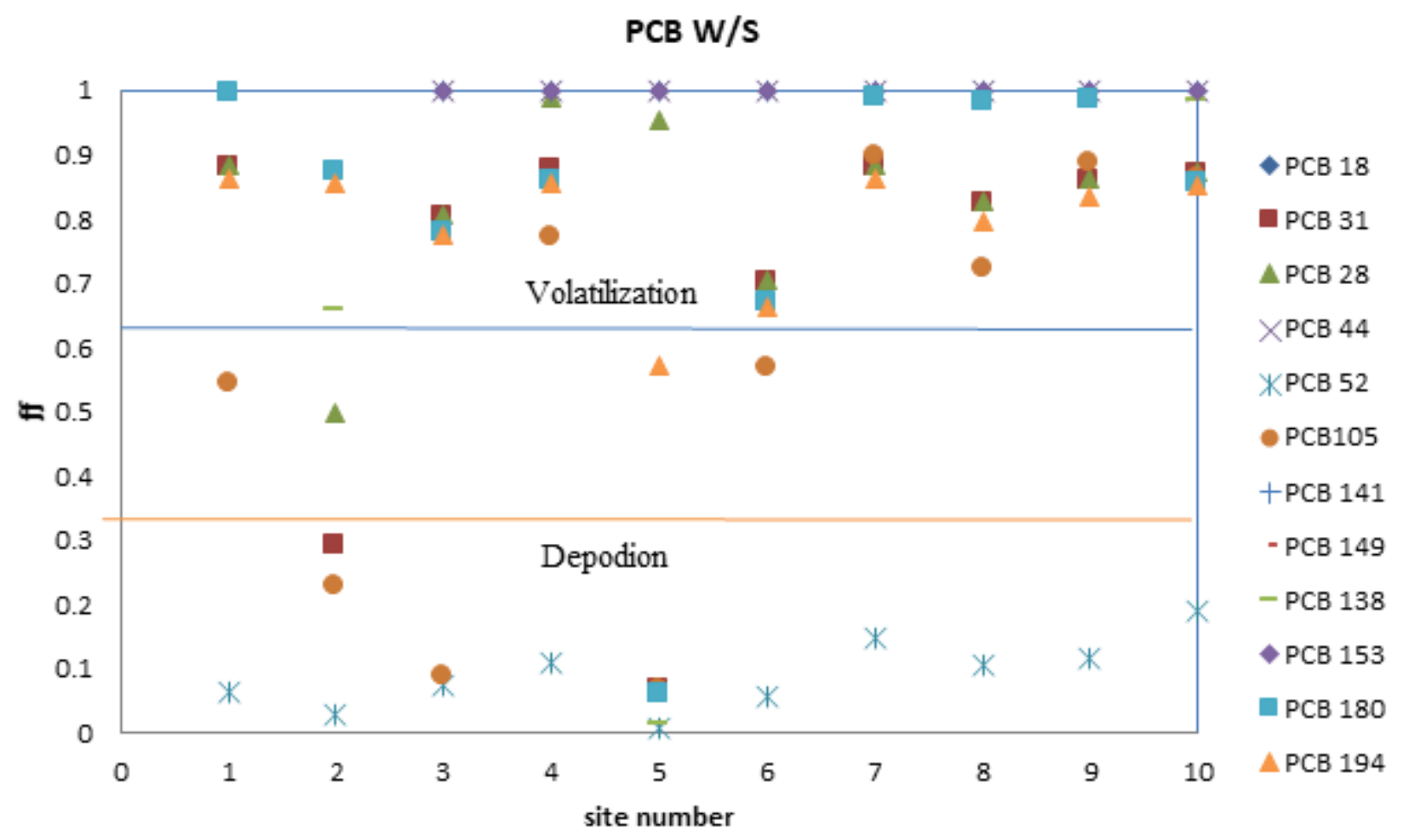

Figure 6

Chart of fugacity index of the common surface of water and sediments of PCB compounds in the coastal stations of the study area 